
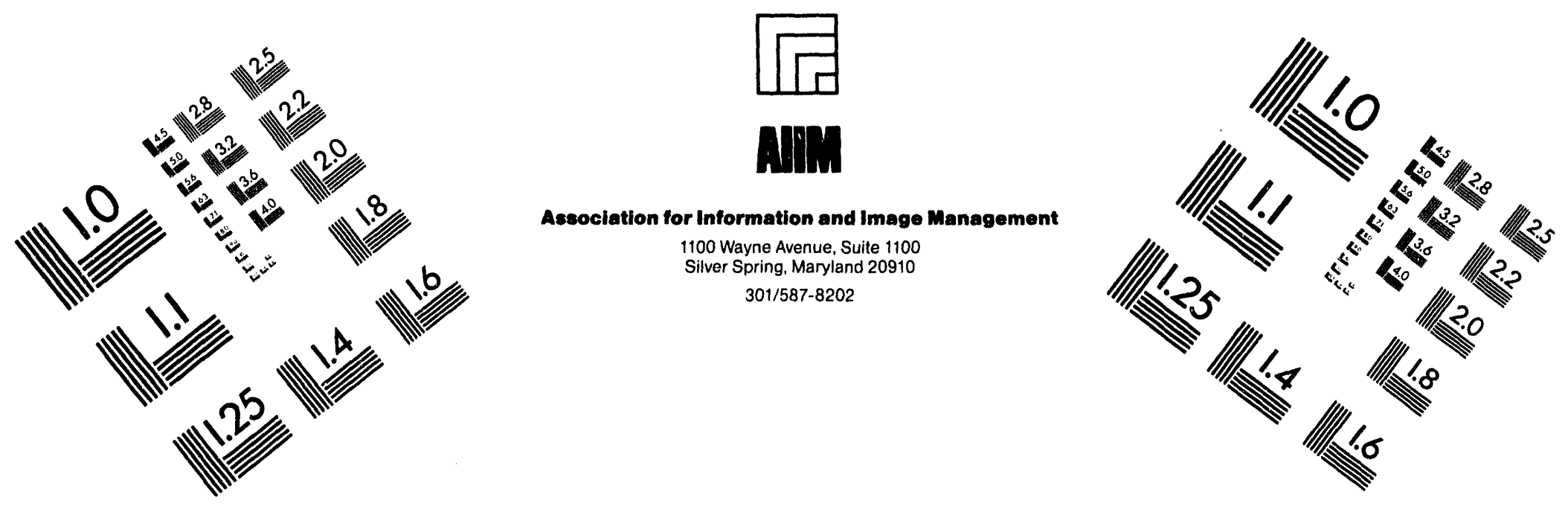

\title{
Centimeter
}

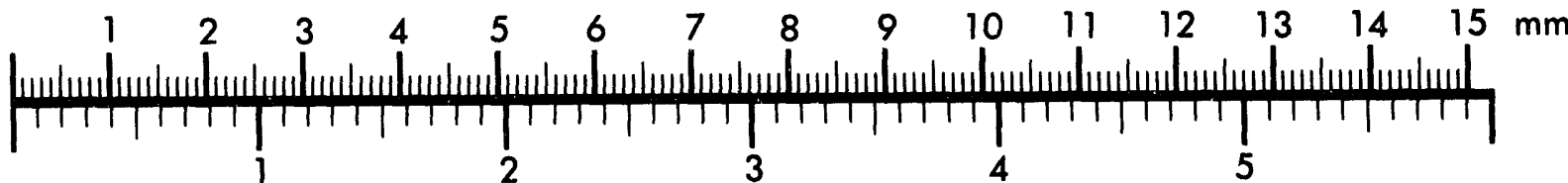
Inches
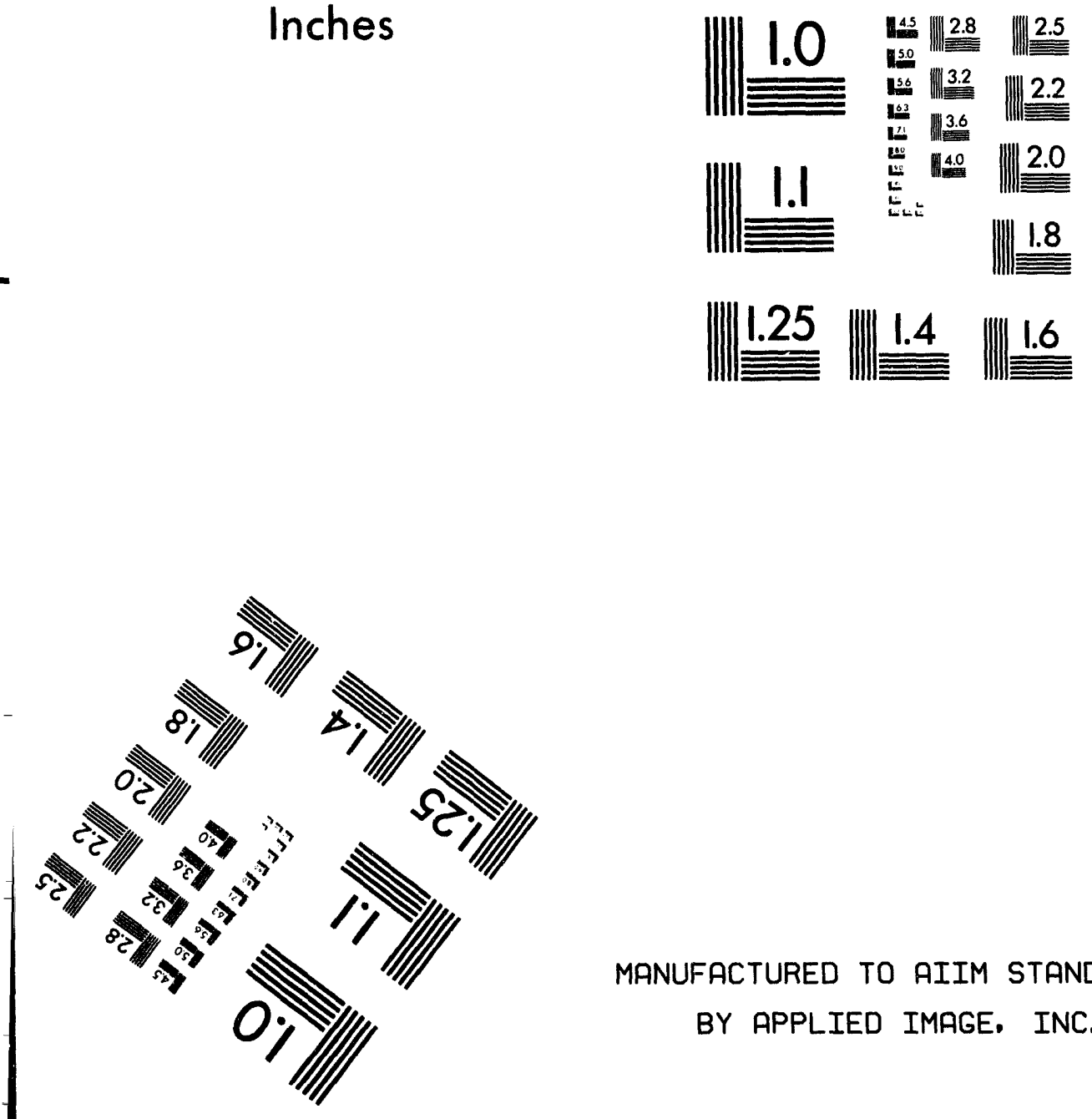

MANUFACTURED TO AIIM STANDARDS

BY APPLIED IMAGE, INC.

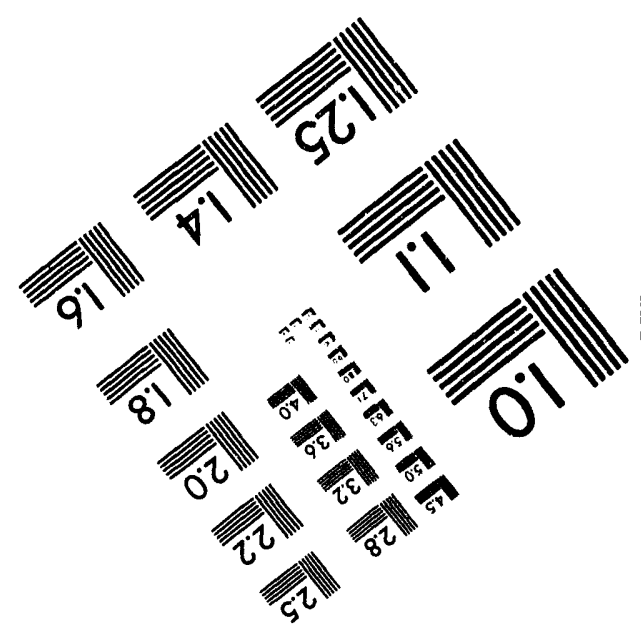



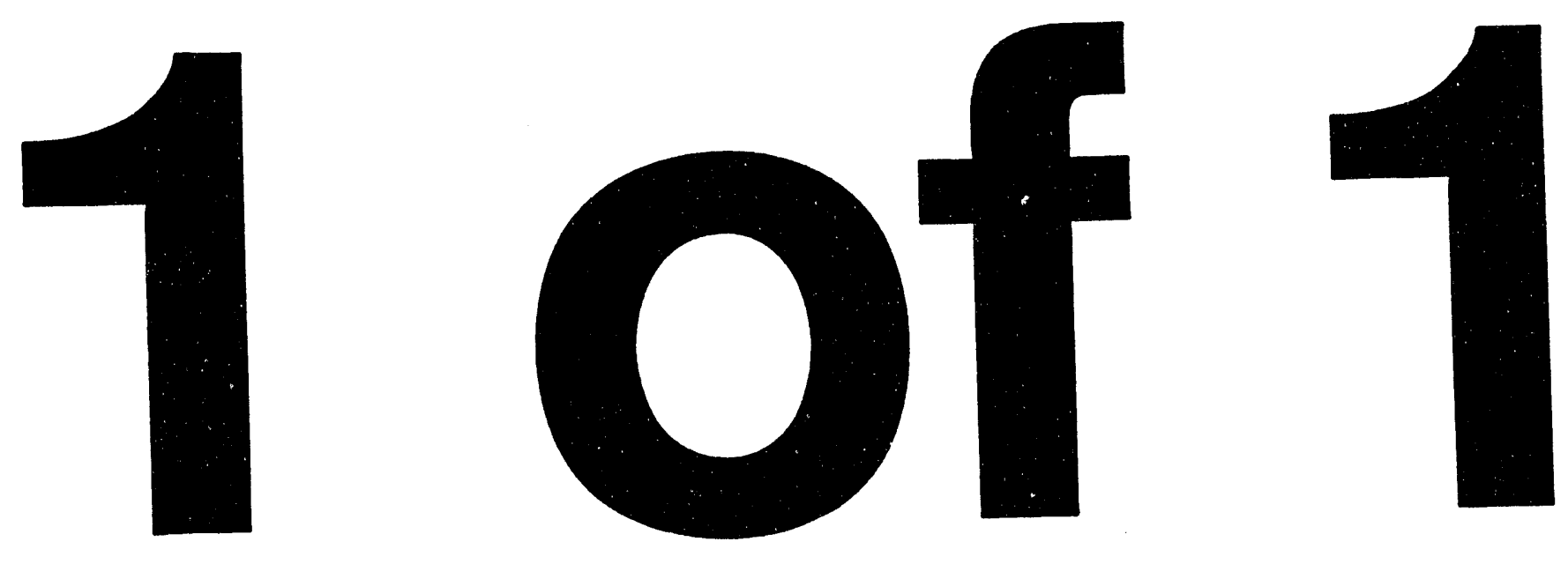


\title{
$\operatorname{Cos}-9405193--2$
}

UCRL-JC-117600

PREPRINT

\section{Overview on Superplasticity Research on Small-Grained Materials}

\author{
Oleg D. Sherby \\ T.G. Nieh \\ J. Wadsworth
}

This paper was prepared for submittal to the International Conference on Superplasticity in Advanced Materials ICSAM-94

Moscow, Russia

May 26, 1994

July 1994

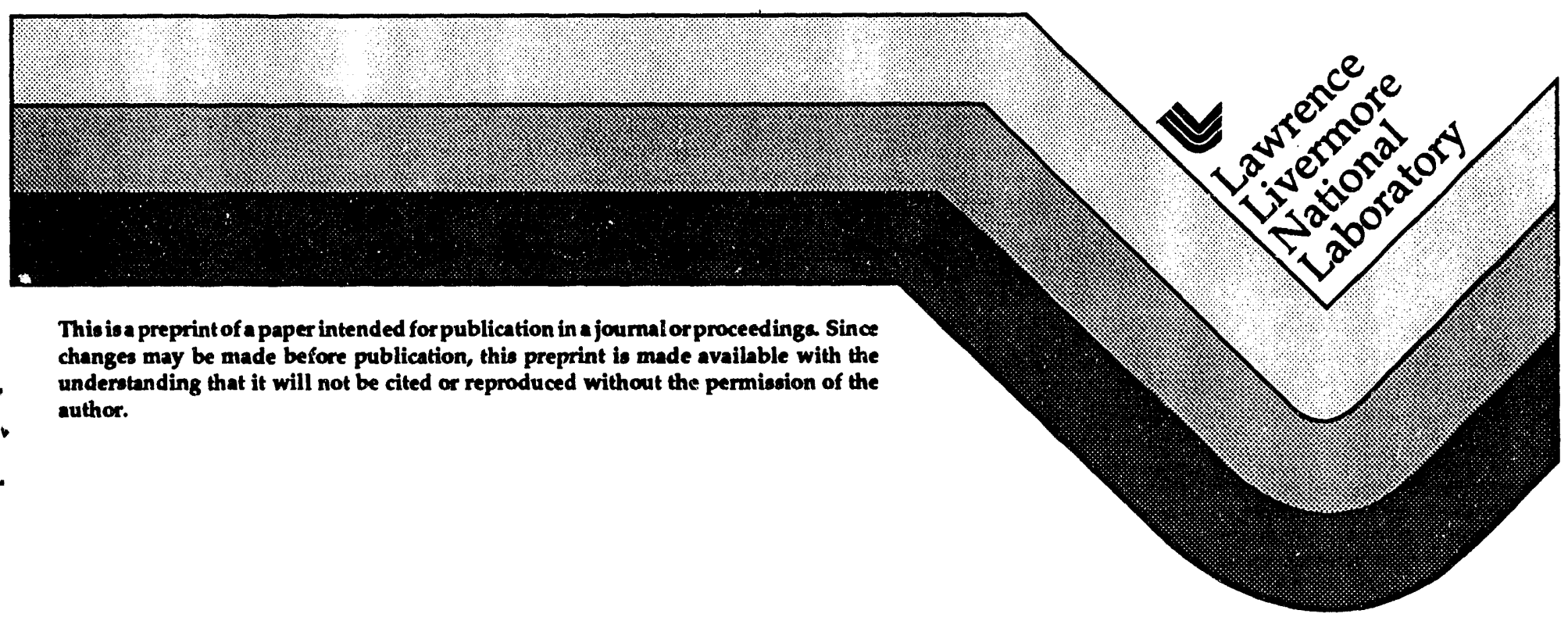

\section{MASTER}




\section{DISCLAIMER}

This document was prepared as an account of work sponsored by an agency of the United States Government. Neither the United States Government nor the University of California nor any of their employees, makes any warranty, express or implied, or assumes any legal liability or responsibility for the accu racy, completeness, or usefulness of any information, apparatus, product, or process disclosed, or represents that its use would not infringe privately owned rights. Reference herein to any specific commercial products, process, or service by trade name, trademark, manufacturer, or otherwise, does not necessarily constitute or imply its endorsement, recommendation, or favoring by the United States Government or the University of California. The views and opinions of authors expressed herein do not necessarily state or reflect those of the United States Government or the University of California. and shall not be used for advertising or product endorsement purposes. 


\title{
OVERVIEW ON SUPERPLASTICITY RESEARCH ON SMALL-GRAINED MATERIALS
}

\author{
Oleg D. Sherby*, T.G. Nieh**, and J. Wadsworth** \\ * Dept. of Materials Science and Engineering, Stanford University, Stanford, CA. 94305, USA \\ ** Department of Chemistry and Materials Science, Lawrence Livermore National Laboratory, \\ P.O. Box 808, L-350, Livermore, CA. 94551-9900, USA
}

\begin{abstract}
Superplasticity is generally associated with fine grains, grain boundary sliding, and high tensile ductility at elevated temperature. This paper reviews some of the recent important findings in fine-grained superplasticity, including the areas of superplastic ceramics and of high-strain-rate superplasticity (HSRS). Deformation mechanism maps are shown to be powerful tools for predicting the conditions where HSRS can be expected. Ultrafine grained materials, processed economically, remain an important objective in achieving HSRS. Threshold stresses, observed in fine-grained superplastic materials, are shown to be functions of temperature and grain size but their origin, however, remains obscure. Quasi-superplastic materials, with a strain-rate-sensitivity exponent of $m=0.33$, are shown to have high elongations, and have considerable promise for netshape isothermal forming of sheet and bulk components.
\end{abstract}

\section{INTRODUCTION}

The modern study of superplasticity has its origin in the work of Bochvar and Sviderskaya [1], who coined the term "sverhplastichnost" [ultrahigh plasticity] in their 1945 paper on Al-Zn alloys. Apparently the term "superplasticity" appeared for the first time in the English language in a 1959 paper by Lozinsky and Simeonova [2] on the subject of "Superhigh Plasticity of Commercial Iron under Cyclic Fluctuations of Temperature". And, the first book on superplasticity appeared, in 1969, written by A.A. Presnyakov, entitled "Superplasticity in Metals and Alloys" [3].

Although, it is commonly thought that superplasticity is a relatively recently-discovered phenomenon, Wadsworth and Sherby [4] have speculated that the phenomenon may have had its first application in ancient times. Figure 1 is a perspective of the historical context of superplasticity with respect to the modern time frame. Ancient bronzes, containing as much as $10 \%$ arsenic, could have been superplastic. This is because these bronzes could have had two phases, allowing for processing into fine-grained materials, permitting superplastic hand-forging them into intricate shaped objects. Although there is no direct evidence for this speculation, there is a great likelihood that the ancient steels of Damascus, in use from $300 \mathrm{BC}$ to the late 19th century, were superplastic. This is because, Wadsworth and Sherby $[5,6]$ have shown, these steels are very similar in composition to modern ultrahigh carbon steels (UHCSs) which are known for their superplastic characteristics [7]. When a modern ultrahigh carbon steel is processed to show a visible damask, simulating the surface markings of ancient swords, the steel is superplastic $[8,9]$. Figure 2 shows the microstructure of a $1.8 \% \mathrm{C}$ steel processed to show a visible wood-like damask. Adjacent to the micrograph is a sample of this UHCS material exhibiting over $300 \%$ elongation when tested at $750^{\circ} \mathrm{C}$. Strain-rate-change tests done on the material showed a strain-rate-sensitivity exponent about equal to 0.4 [8]. These results suggest that some of the ancient Damascus steel weapons were probably superplastic at elevated temperature. 
The increasing interest in superplasticity during the past 30 years is evidenced by the number of publications per year as shown in Figure 3. In 1963, there was only one publication, in 1973, there were 55 publications, in 1983, there were 140 publications, and in 1991, over three hundred publications. The program to the present symposium lists 70 presentations and 99 posters, attesting to the continued international interest in this field. In Figure 3, the conspicuous entrance of superplastic ceramics is illustrated beginning ins 1986, with a similar increase in interest over subsequent years to that noted in metals 30 years earlier. Many reviews are available on the subject of superplasticity and superplastic forming and, because of limited space, it is not intended to list these papers. However, reference [4] gives such references up to 1990. The following subsections cover a discussion on superplastic ceramics, on high strain-rate superplasticity, on threshold stresses associated with superplastic materials, and on quasi-superplastic materials observed in many solid solution alloy systems.

\section{SUPERPLASTIC CERAMICS}

In a major breakthrough, a ceramic (yttria stabilized zirconia) and a ceramic composite (yttria stabilized zirconia containing alumina) have been shown to be superplastic in tension tests by Wakai et al $[10,11]$. Elongations up to $200 \%$ were recorded. Nieh, Wadsworth et al, working with the same composition materials, showed that elongations as high as $800 \%$ can be achieved [12-14]. The basis of the success achieved was that the grain size was exceptionally fine, and in the extreme case, a size of $0.3 \mu \mathrm{m}$ was produced. Both sets of authors emphasized and showed that the elongation was a function of temperature and of strain rate, decreasing dramatically with increasing strain rate and with decreasing temperature. Since all tests were done in the high strainrate-sensitivity range (the strain-rate-sensitivity exponent was equal to 0.5 or greater), these results show that a high strain rate sensitivity is a necessary but not sufficient condition for achieving superplasticity in fine-grained ceramics.

Kim et al [15-18] have shown that the tensile ductility of superplastic ceramics is a function of the flow stress at elevated temperature, increasing with a decrease in the flow stress. Specifically, a linear correlation was found between the true fracture strain, $\varepsilon f$, and the logarithm of flow stress, $\sigma$, for a number of superplastic ceramics in the temperature and stress range where the strain-ratesensitivity exponent is equal to or greater than 0.5 . Chen and Xue showed similar trends [19]. Figure 4 shows such a plot for various superplastic ceramics [15,18]. It can be noted from the graph that all the different ceramic materials exhibit a similar value of the slope. This slope is attributed to the rate of damage accumulation as a function of plastic strain from the common deformation mechanism of grain boundary sliding [15,16]. A fracture mechanics model by Kim et al [15], based on the above concept, together with a brittle fracture criterion (the critical stress intensity factor, $K_{c}$ ), led to the following fracture strain relation:

$$
\varepsilon_{f}=\ln \left[K_{c} / \pi d \sigma^{-2}\right]^{1 / q}
$$

where $d$ is the grain size. The value of $q$ is equal to the reciprocal of the slope of the curves in Figure 4. The value of $q$ is about seven. The difference in tensile ductility at a given flow stress for the various ceramic materials shown in Figure 4 have been related to differences in grain size (Eq.1), and to the elastic modulus as well as to differences in the surface and grain boundary energies (related to the value of $K_{c}$ ) [15-18]. The fracture mechanics model quantitatively predicts the grain size effect. An example for polycrystalline alumina and its composites is given in Figure 5, where $\varepsilon_{f}$ is plotted as a function of grain size [18]. Excellent agreement is observed between the experimental data and equation [1] for alumina containing a small amount of $\mathrm{MgO}$ as can be seen with the lowest curve in the figure. That is, the predicted slope is in agreement with experimental data. The other curves shown in the figure, however, indicate that other factors contribute to the fracture strain. These differences are attributed to differences in the critical stress intensity factor, $K_{c}$. Thus, ic is postulated that the addition of $\mathrm{MgO}$ increasess the surface energy and/or decreases the grain boundary energy, and thus increases the value of $K_{c}$. For example, $\mathrm{MgO}$ segregation to the grain boundaries of alumina can alter the grain boundary structure such that the grain boundary energy is decreased. In the case of the enhancement of tensile ductility of alumina by zirconia (uppermost curve in Figure 5), it is postulated that addition of zirconia as a 
second phase increase the number of alumina-zirconia grain boundaries which have a low grain boundary energy $[15,18]$. Thus, crack formation is inhibited and the fracture process is delayed.

It is proposed that metallic-like behavior can be achieved in ceramic-base materials. An example showing this metallic-like trend is given in Figure 6 for an yttria-stabilized zirconia containing 20 weight percent of alumina. It can be seen that when this material is tested near the melting temperature (the eutectic temperature) the tensile ductility is insensitive to the stress, just as is observed in metallic-base superplastic materials [15]. When the material, however, is tested at a lower homologous temperature the trend of ductility with stress is the same as that shown in Figure 4. The observed metallic-like behavior is attributed to the presence of stable ultra-fine grains, and to the very high temperature of testing where recovery processes delay the formation of voids and cracks with straining. In these cases, even necking is observed prior to final failure (a remarkable observation for oxide ceramics). This encouraging result would suggest that it may eventually be possible to achieve high-strain-rate superplasticity in ceramic materials.

\section{HIGH-STRAIN-RATE SUPERPLASTICITY (AND THRESHOLD STRESSES)}

It is well established that superplastic forming has considerable potential in industrial manufacturing. However, the commercial utilization of superplastic forming has been limited by the low strain rates $\left(10^{-4}\right.$ to $\left.10^{-3} \mathrm{~s}^{-1}\right)$ generally associated with optimum superplastic ductility. The motivation for high strain rate superplasticity (HSRS) is economics. Obviously, the longer the parts take to form, the more expensive they are. Typical superplastic materials have small grain sizes $(1$ to $10 \mu \mathrm{m})$ and $\mathrm{n}$ principle a reduction in grain size offers the advantage of giving high ductilities to failure at high strain rates and/or low temperatures. Attempts are now in progress in several laboratories to reduce the grain size by fabricating nanocrystalline structures or by producing submicrometer-grained (SMG) microstructures in conventional alloys by intense plastic strain. High strain-rate superplasticity (HSRS) was first discovered, explored, and analyzed by Nieh, Wadsworth and their colleagues [20-21] beginning in 1984. Subsequent work by these authors with Mukherjee and Bieler lead to further confirmation of high strain-rate superplasticity $[22,23]$. The most recent studies on this subject are by Higashi and his colleagues who tested a number of PM and MA alloys [24-26].

Deformation mechanism maps are useful tools to assess the mechanisms that will control plastic flow depending on temperature, strain rate and grain size. An example of such a map is given in Figure 7. The four plots show the strain rate as a function of homologous temperature for four different grain sizes $(100 \mu \mathrm{m}, 10 \mu \mathrm{m}, 1 \mu \mathrm{m}$, and $0.1 \mu \mathrm{m})$. The maps are based on constitutive equations that describe plastic flow controlled by diffusion-controlled dislocation creep (power law creep or Harper-Dorn creep), by grain boundary sliding, and by diffusional creep (Nabarro-Herring creep). The constitutive equations used to develop these maps are given elsewhere [27-29]. The shaded area in each of the four diagrams given in Figure 7 refers to plastic flow controlled by grain boundary sliding, and therefore where fine-grained superplasticity can be expected. A dotted horizontal line is shown at $10 \%$ per second, which can be considered as the beginning of high-strain-rate superplasticity. As can be seen, for a grain size of $100 \mu \mathrm{m}$, superplastic flow can never be achieved under any conditions. At $10 \mu \mathrm{m}$, superplastic flow at $10 \%$ per second can only be achieved at a very high homologous temperature $\left(0.85 \mathrm{~T}_{\mathrm{m}}\right)$, where grain growth and oxidation, however, can eliminate the potential of attaining superplastic behavior. At $1 \mu \mathrm{m}$, superplasticity at $10 \%$ per second can be expected at temperatures as low as $0.6 \mathrm{~T}_{\mathrm{m}}$. And, at $0.1 \mu \mathrm{m}$, the exciting prospect of achieving superplasticity at high strain rates at low homologous temperatures $\left(0.4 \mathrm{~T}_{\mathrm{m}}\right)$ is predicted.

An application of deformation mechanism maps to assess the new field of high-strain-rate superplasticity in aluminum-base alloys is shown in Figure 8. This figure illustrates deformation mechanism maps at a prescribed homologous temperature $\left(0.8-0.9 \mathrm{~T}_{\mathrm{m}}\right)$, with the grain size plotted as a function of modulus-compensated stress, Fig. 8A, and as a function of strain rate, Fig. 8B. The three different types of aluminum alloys are seen to fall in the predicted range where grain boundary sliding (GBS) is expected, and therefore where superplastic flow will be observed. As can be seen in the figure, fine-grained ingot-processed aluminum alloys [IM] exhibit superplasticity only in the strain rate range of about $10^{-4} \mathrm{~s}^{-1}$, whereas the finer grained powder-processed aluminum alloys (PM) exhibit superplasticity at higher strain rates $\left(10^{-2}\right.$ to $\left.1 \mathrm{~s}^{-1}\right)$. The recently- 
developed mechanically-alloyed, ultra-fine grained aluminum alloys (MA) exhibit superplasticity at strain rates as high as $10^{2}$ per second.

Figure 9 illustrates the typical flow stress and tensile ductility relations with strain rate for a fine-grained $(1.2 \mu \mathrm{m}) \mathrm{Al}-\mathrm{Mg}$-Si composite containing $20 \% \mathrm{Si}_{3} \mathrm{~N}_{4}$ particles. High strain rate sensitivity exponents, in the order of 0.5 , are observed at high strain rates. A maximum elongation of nearly $700 \%$ was obtained at $2 \%$ at $833 \mathrm{~K}$. Powder processing was used to make this particular MMC material. An additional feature is to be noted in Figure 9. Threshold stresses are clearly evident, which are functions of temperature, increasing with decreasing temperature. It is generally accepted that this threshold stress is associated with the inhibition of the grain boundary sliding process, but a quantitative prediction of its absolute value based on microstructural features have not evolved, and its strong function with temperature remains perplexing. Higashi et al have shown that the grain size is an important variable in increasing the maximum strain rate for highstrain-rate superplasticity. Figure 10 shows the relation between logarithm of the optimum strain rate for superplastic flow and the grain size (plotted as logarithm of reciprocal grain size). An optimistic prediction is made for two phase aluminum-base materials with nano-size grains, where superplastic flow at $10^{3}$ to $10^{4}$ per second can he expected.

The precise mechanism of superplastic flow at high strain rates is not fully understood, although it is generally agreed that fine grains are necessary. Nieh and Wadsworth consider that some grain boundary or interface boundary melting is important to achieve HSRS, and that adiabatic heating during deformation may play an important role. Muhkerjee and Bieler consider that a type of Class I solid-solution behavior is occurring where a strain rate sensitivity exponent of 0.33 is expected (a solute-drag controlled dislocation creep process); no grain size effect is considered in their model. Higashi et al consider the need to introduce a grain boundary sliding model involving a threshold stress, but a traditional Ball-Hutchinson type GBS relation [30] does not lead to a good prediction with the data generated with HSRS materials. Kim et al [31] have shown that the GBS model of Ball and Hutchinson, when modified to take into account subgrain boundaries as sinks for moving dislocations allows for good quantitative prediction of the HSRS data of Higashi $e t$ al.

A threshold stress for plastic flow in polycrystalline solids has often been introduced to understand and interpret deformation mechanisms at elevated temperature. Such behavior is often ascribed to athermal contributions to flow involving dislocation motion. An example is the Orowan dislocation bowing stress, and another is the Rosler-Artz stress for unlocking a dislocation from a particle. These models, however, cannot explain the temperature dependence of the threshold stress. Threshold stresses have been used to fit data to agree with diffusional creep [32], with diffusion-controlled dislocation creep [33-34] and, as noted in this paper, with grain boundary sliding. A major common microstructural feature in all these cases, is that the materials studied are usually PM or MA processed materials, and as such have fine-structure and/or finegrains. In all cases, it would appear that the threshold stress is a strong function of grain size, increasing in magnitude with a decrease in grain size. No quantitative micromechanism models have been developed to explain satisfactorily the threshold stress in all three deformation mechanisms.

\section{QUASI-SUPERPLASTICITY IN METALLIC-BASE ALLOYS}

High strain-rate-sensitivity may be achievable in metallic materials by a mechanism that does not require grain-boundary sliding and fine grains. These are the Class I solid solution alloys in which the glide segment of the glide/climb dislocation creep process is rate-controlling because solute atoms impede dislocation motion. These alloys have an intrinsically high strain-rate sensitivity exponent, $\mathrm{m}=0.33$, and elongations in the order of 200 to $400 \%$ are observed. Sherby and Wadsworth [27] have listed a number of alloys which exhibit $m=0.33$, and whenever available, the maximum elongation observed is also often recorded. The extended elongations inherent in these solid solution alloys would suggest that they be classified as quasisuperplastic materials (i.e. resembling-superplasticity or superplastic-like).

Superform Metals, Inc. have been gas-pressure forming complex sheet shapes from a number of commercial aluminum alloys. Four different composition aluminum alloys $(2004,7475,8090$ 
and 5083) have been used. Two-thirds of all gas-pressure formed parts made by Superform are made with 5083. This commercial alloy contains about $4.5 \% \mathrm{Mg}$ and $0.5 \% \mathrm{Mn}$ and has a grain size of $25 \mu \mathrm{m}$. The deformation mechanism for this alloy is solute-drag-controlled dislocation creep, and the strain-rate-sensitivity exponent is about 0.3 . Its tensile ductility is typically about 200 to $250 \%$ which gives sufficient ductility for Superform to manufacture this alloy into intricate sheet components. The other three aluminum alloys, 2004, 7475 and 8090 , are fine-grained and exhibit $m$ values in the order of 0.5. These interesting statistics reveal that most Superform components are made with a quasi-superplastic material.

Figure 11 illustrates some bulk formed components made in Russia which were probably also formed under quasi-superplastic conditions. The sample on the left is a relatively coarse-grained $\mathrm{Fe}-\mathrm{Al}$ alloy formed isothermally at $800^{\circ} \mathrm{C}$ into an remarkably intricate electrical connector component [about 2 minutes to form the part]. The sample in the middle is a section of an aluminum piston, quasi-superplastically rormed at $450^{\circ} \mathrm{C}$, made from an $\mathrm{Al}-\mathrm{Mg}$-Si coarse-grained material, at a strain rate of $10^{-2}$ per second (where $\mathrm{m}$ was equal to about 0.35 ). The part on the right is an aluminum alloy which was bulk formed from an aluminum alloy of un specified composition; the part was made at Chelyabinsk for use as part of an automotive wheel.

Although quasi-superplasticity is achievable with Class I solid solution alloys, it is to be pointed out that such materials generally do not have high strength at low temperatures. Therefore, these materials are used mostly as secondary structural components. In primary structural components, high to ultrahigh strengths are desired at low temperature. In this case, ultrafinegrained materials with ultra-fine second phases are naturally choices. Such materials are not only likely to be truly superplastic at elevated temperature, but can also have improved elastic stiffness, be lighter, with good to very good tensile ductility properties at low temperatures. An example for aluminum alloys are the light $\mathrm{Al}-\mathrm{Mg}-\mathrm{Li}$ alloys made by mechanical alloying procedures [25]. Another example is ultrahigh carbon steel [7] which is superplastic at elevated temperatures and has ultrahigh strength and good tensile ductility at room temperature.

\section{ACKNOWLEDGMENTS}

The authors wish to express their sincerest thanks to the many colleagues who have collaborated with them on the subject of superplasticity. Discussions with Drs. Woo Jin Kim, Oleg Smirnov, Oscar Kaibyshev, Kenji Higashi and Mr. Eric Taleff are greatly appreciated. Much of the work of the authors has been sponsored by the Office of Naval Research (Dr. George Yoder, monitor) and the Army Research Office (Drs. Wilbur Simmons and Andrew Crowsonq). Their interest and faith in our work are acknowledged with gratitude. The authors (TGN and JW) were supported by the U.S. Department of Energy at Lawrence Livermore National Laboratory under contract No. W-7405-Eng-48.

\section{REFERENCES}

1. A.A. Bochvar and Z.A. Sviderskaya, Izv. Nauk SSSR, Otd. Te'lln. Nauk, 9, 821 (1945).

2. M.G. Lozinsky and I.S. Simeonova, Acta Metall., 7, 709 (1959).

3. A.A. Presnyakov, Superplasticity in Metals and Alloys, (Nauka, Alma Alta, 1969, in Russian).

4. O.D. Sherby and J. Wadsworth, in Superplasticity in Metals, Ceramics and Intermetallics, MRS Proc. No.196, 3, edited by، M.J. Mayo, M. Kobayashi and J. Wadsworth, Materials Rescarch Society, Pittsburgh, PA., (1990)

5. J. Wadsworth and O.D. Sherby, Prog. Mater. Sci. 25, 35 (1980).

6. O.D. Sherby and J. Wadsworth, Sci. Amer. 252, 112 (1985).

7. D.R. Lesuer, C.K. Syn, A. Goldberg, J. Wadsworth and O.D. Sherby, J. of Metals, 45,40 (1993).

8. O.D. Sherby, Third International Congress on Damascene Steel, June 10-14, 1993, Westfalisches Freilichtmuseum, Hagan, Germany, to be published in Proceedings of the Congress, 1994.

9. Oleg D. Sherby and Jeffrey Wadsworth, research in progress, Stanford University, 1994.

10. F. Wakai, S. Sakaguchi and Y. Matsuno, Adv. Ceramic Mater., 1, 259 (1986). 
11. F. Wakai and H. Kato, Adv. Ceramic Mater., 2, 71 (1987).

12. T.G. Nieh, C.M. McNally and J. Wadsworth, Scripta Metall., 22, 1297 (1988).

13. T.G. Nieh, C.M. McNally and J. Wadsworth, Scripta Metall., 23, 457 (1989).

14. T.G. Nieh, J. Wadsworth and O.D. Sherby, in Advanced Synthesis of Engineering Materials, edited by J.J. Morris, E.J. Lavernia, F.H. Fores, 269-275, ASM International, Materials Park, OH, 1993.

15. W.J. Kim, J. Wolfenstine and O.D. Sherby, Acta Metall.Mater., 39 [2], 199 (1991).

16. W.J. Kim, Ph.D. dissertation, Stanford University, Stanford, CA. 1993.

17. W.J. Kim, J. Wolfenstine, O.A. Ruano, G. Frommeyer and O.D. Sherby, Metal. Trans., 23A, 527 (1992).

18. W. J. Kim and O. D. Sherby, J. Amer. Cer. Soc., 1994. submitted for publication.

19. I.W. Chen and L.A. Xue, J. Am. Ceram. Soc., 73, 2585 (1990).

20. T.G. Nieh, C.A. Henshall and J. Wadsworth, Scripta Metall., 18, 1405 (1984).

21. T.G. Nieh, P.S. Gilman and J. Wadsworth, Scripta Metall., 19, 1375 (1985).

22. T.R. Bieler, T.G. Nieh, J. Wadsworth and A.K. Mukherjee, Scripta Metall., 22, 81 (1988).

23. T.R. Bieler and A.K. Mukherjee, Mater. Sci. and Engr., A128, 171 (1990).

24. K. Higashi, T. Okada, T. Mukai and S. Tanimura, in Superplasticity in Advanced Materials, 569 , edited by S. Hori, M. Tokizane and N. Furushiro, The Japan Society for Research on Superplasticity, 1991.

25. Kenji Higashi and Mamoru Mabuchi, Advanced Composite Materials, 15086, edited by T. Chandra and A.K. Dhingra, The Metallurgical Society, Warrendale, PA, 1993.

26. M. Mabuchi, K. Higashi, Y. Okada, S. Tanimura, T. Imai and K. Kubo, Scripta Metall., 25, 2517 (1991).

27. O.D. Sherby and J.Wadsworth, Prog. Mater. Sci. 33, 169 (1989).

28. O.A. Ruano, J. Wadsworth and O.D. Sherby, Acta Metall., 36, 1117 (1988).

29. O.A. Ruano, J. Wadsworth and O.D. Sherby, J. Mater. Sci., 20, 3735 (1985).

30. A. Ball and M.M. Hutchinson, Met. Sci. J., 3 , 1 (1969)

31. W.J. Kim, E. Taleff, and O.D. Sherby, research in progress, May 1994.

32. B. Burton, Diffusional Creep of Polycrystalline Materials, Trans. Tech. Publ., 1977.

33. R.S. Mishra and A.B. Pandey, Metall. Trans. 21A, 2089 (1990).

34. G. Gonzalez-Doncel and O.D. Sherby, Acta Metall. Mater., 41, 2797 (1993). 


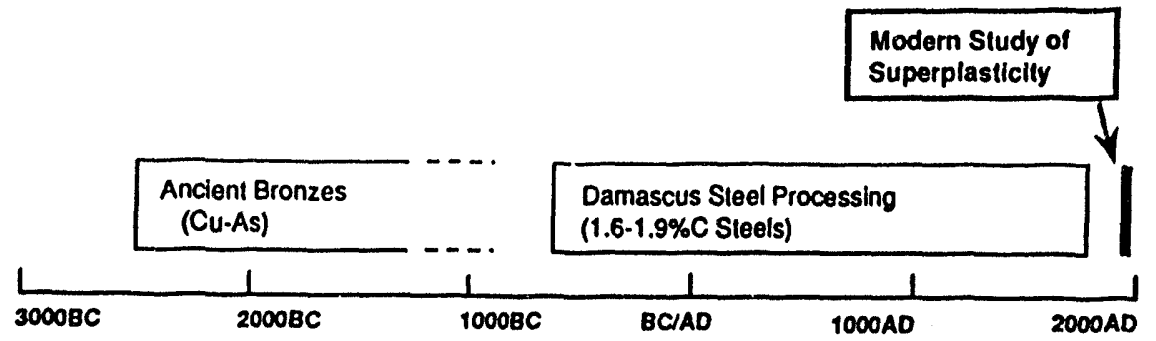

Figure 1. Historical perspective of the development of superplasticity from possible ancient origins to the present time.
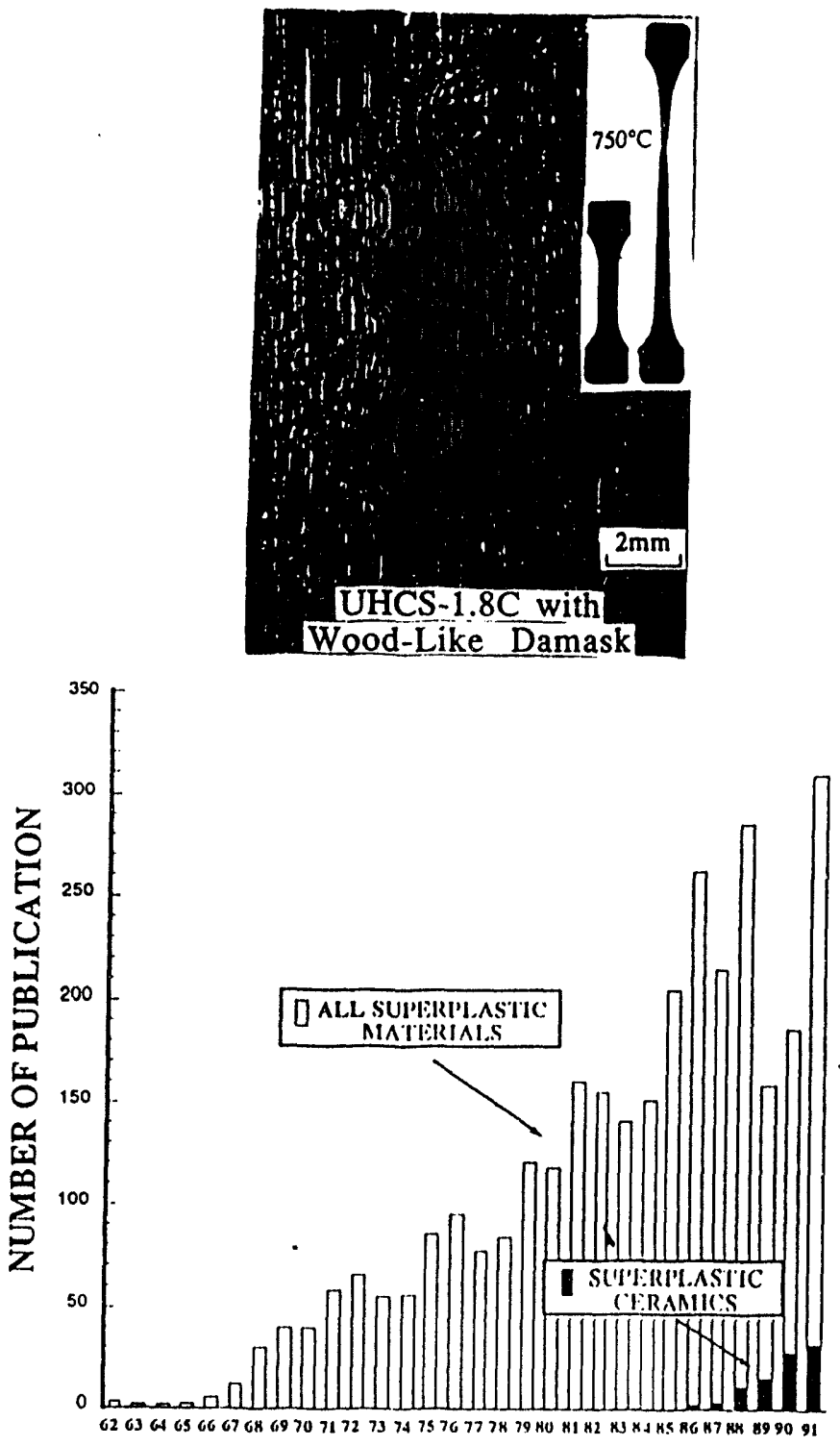

Y'EAR
Figure 2. Ultrahigh carbon steel $(1.8 \% \mathrm{C})$ processed to obtain a wood-like damask exhibits superplastic behavior.
Figure 3. Publications as a function of time illustrating growth of the new field of superplastic ceramics. 

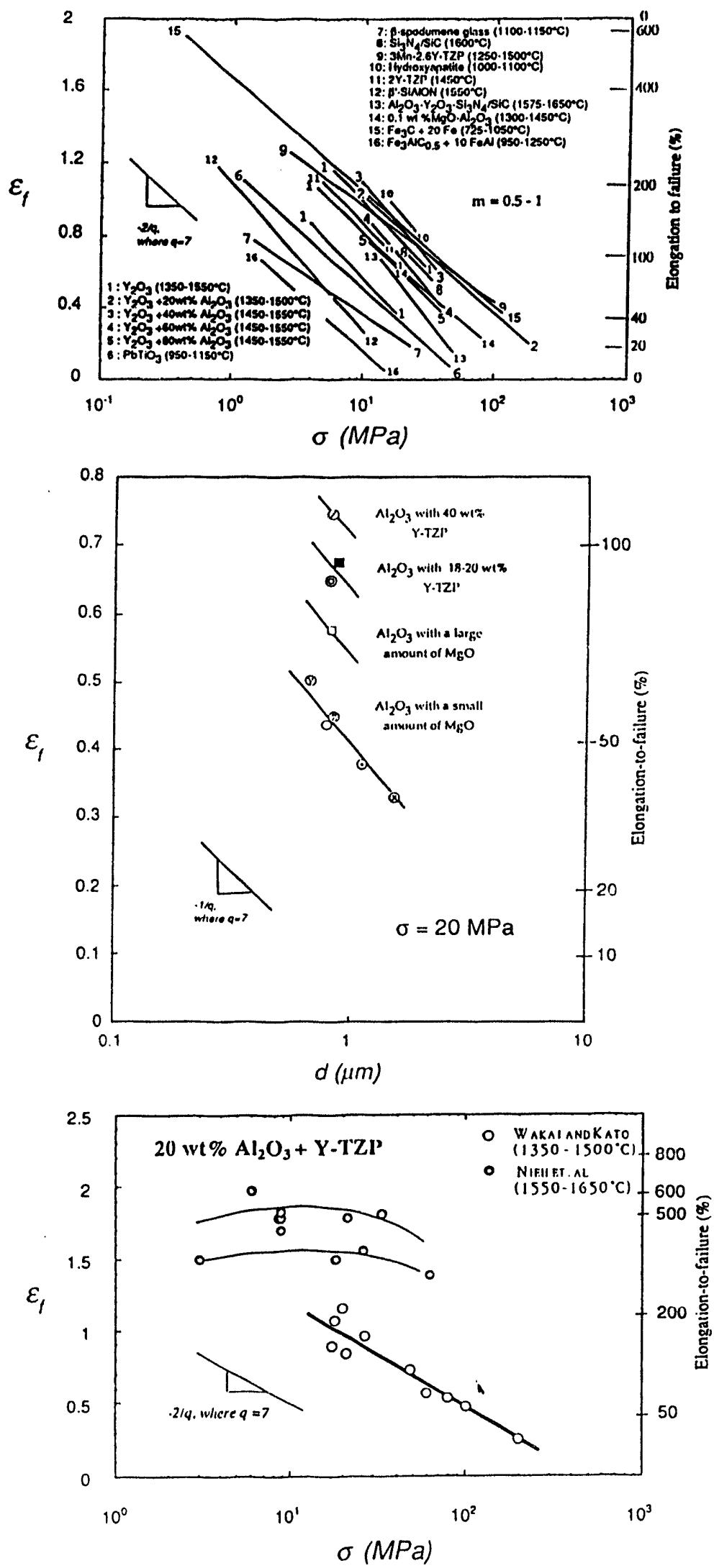

Figure 4. Influence of flow stress on the true fracture strain for fine-grained polycrystalline ceramics in the temperature range where the strain-rate-sensitivity exponent, $m$, is high $(m \geq 0.5)$. [Kim and Sherby (18)]

Figure 5. Influence of grain size on the true fracture strain for different alumina groups at a given flow stress, $20 \mathrm{MPa}$. [Kim and Sherby (18)]

Figure 6. Trure fracture strain of fine-grained Y-TZP+ $20 \mathrm{wt} \%$ $\mathrm{Al}_{2} \mathrm{O}_{3}$ composite as a function of the applied flow stress. 

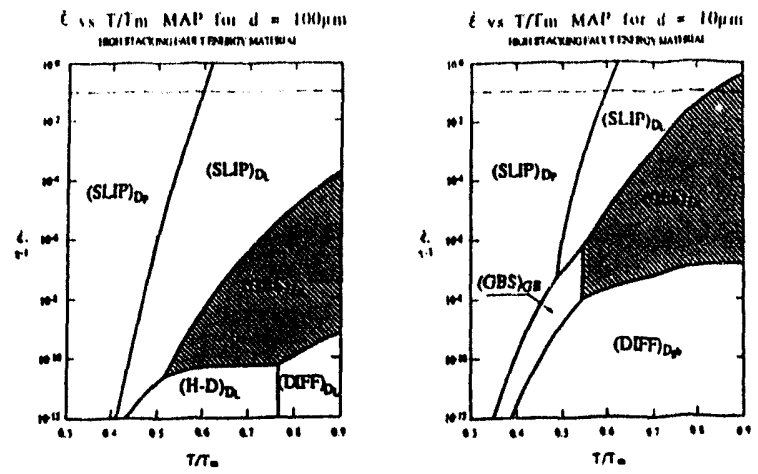

i $\quad T / T_{m}$ MAP for d = l/m

In T/Tm MAP Fon $d=0.1$ mun
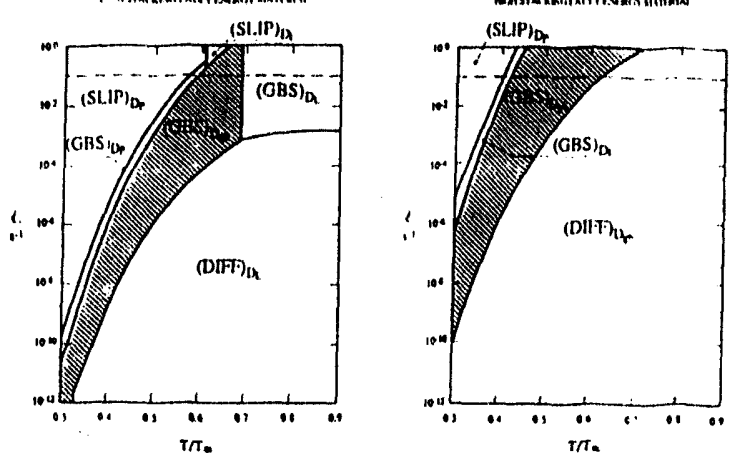

Figure 7. Influence of grain size on deformation mechanism maps.
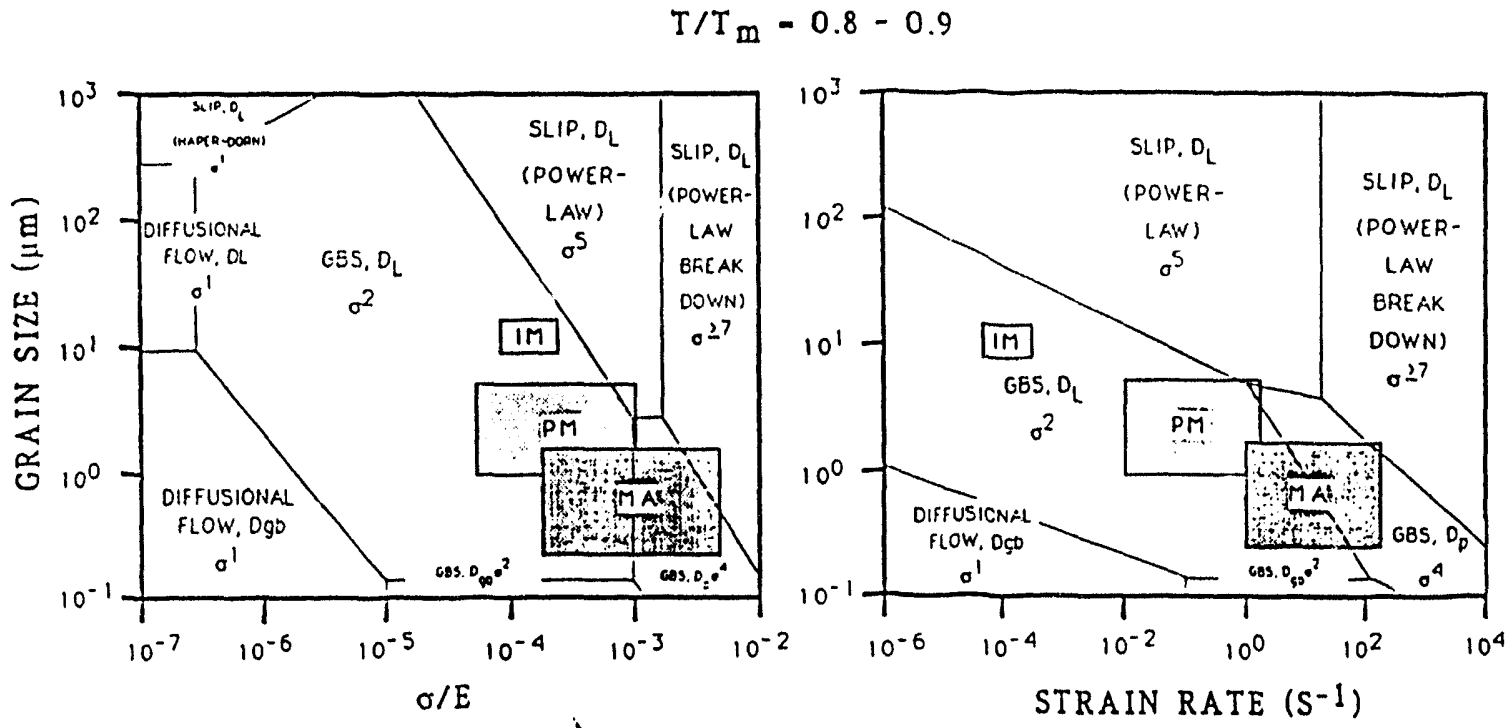

Figure 8. Deformation mechanism map showing regions where diffusional creep, slip (dislocation creep) and grain boundary sliding are obtained as a function of grain size and modulus-compensated stress (left figure) and strain rate (right figure). 


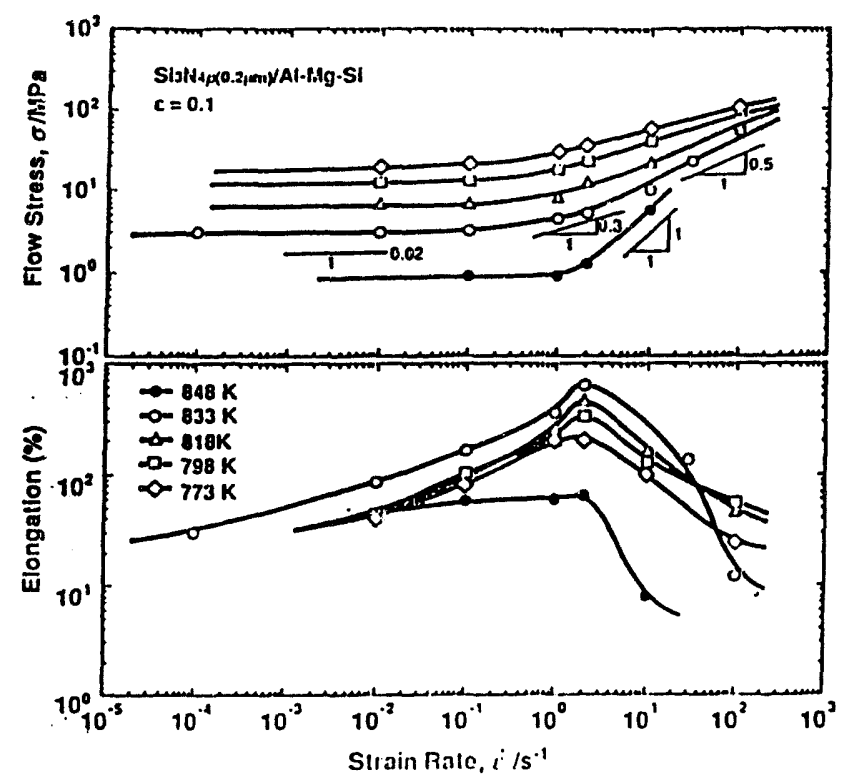

Figure 9. Flow stress and elongation to failure as a function of strain rate for MMC aluminum containing $20 \% \mathrm{Si}_{3} \mathrm{~N}_{4}$ particles.

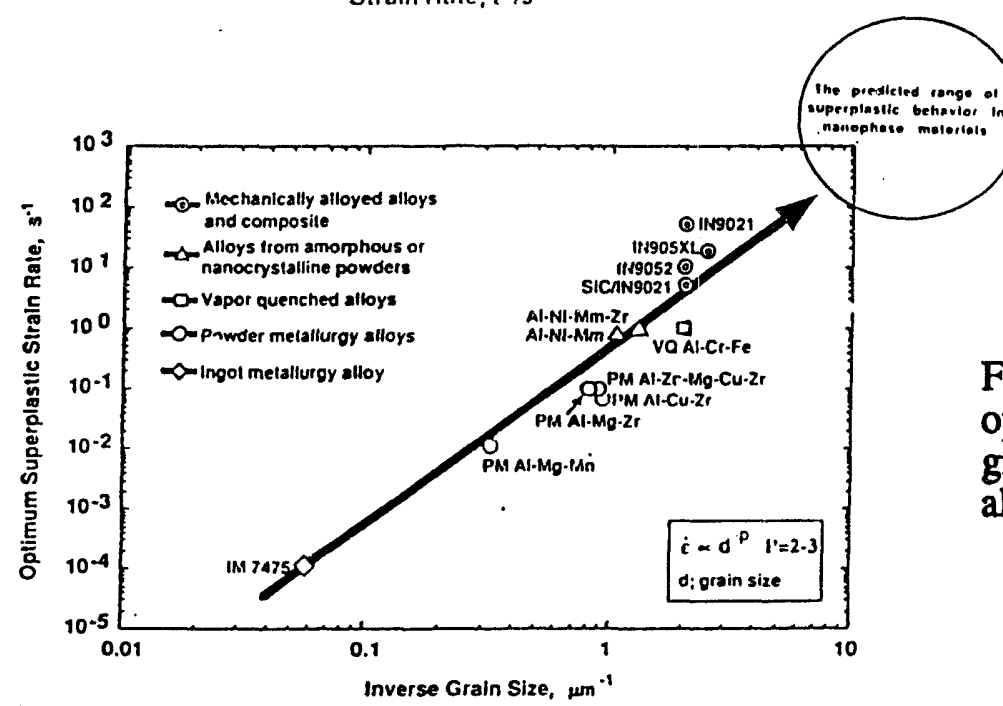

Figure 10. The relationship between optimum superplastic strain rate and grain size for superplastic aluminum alloys produced by different routes.

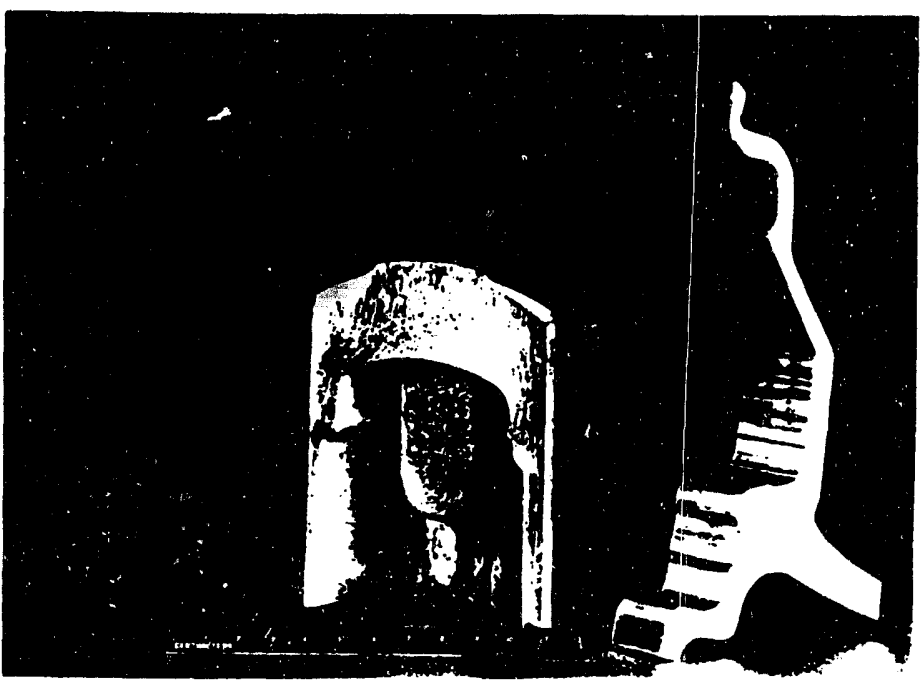

Figure 11. Bulk formed components of aluminum made in Russia under isothermal forming conditions. 

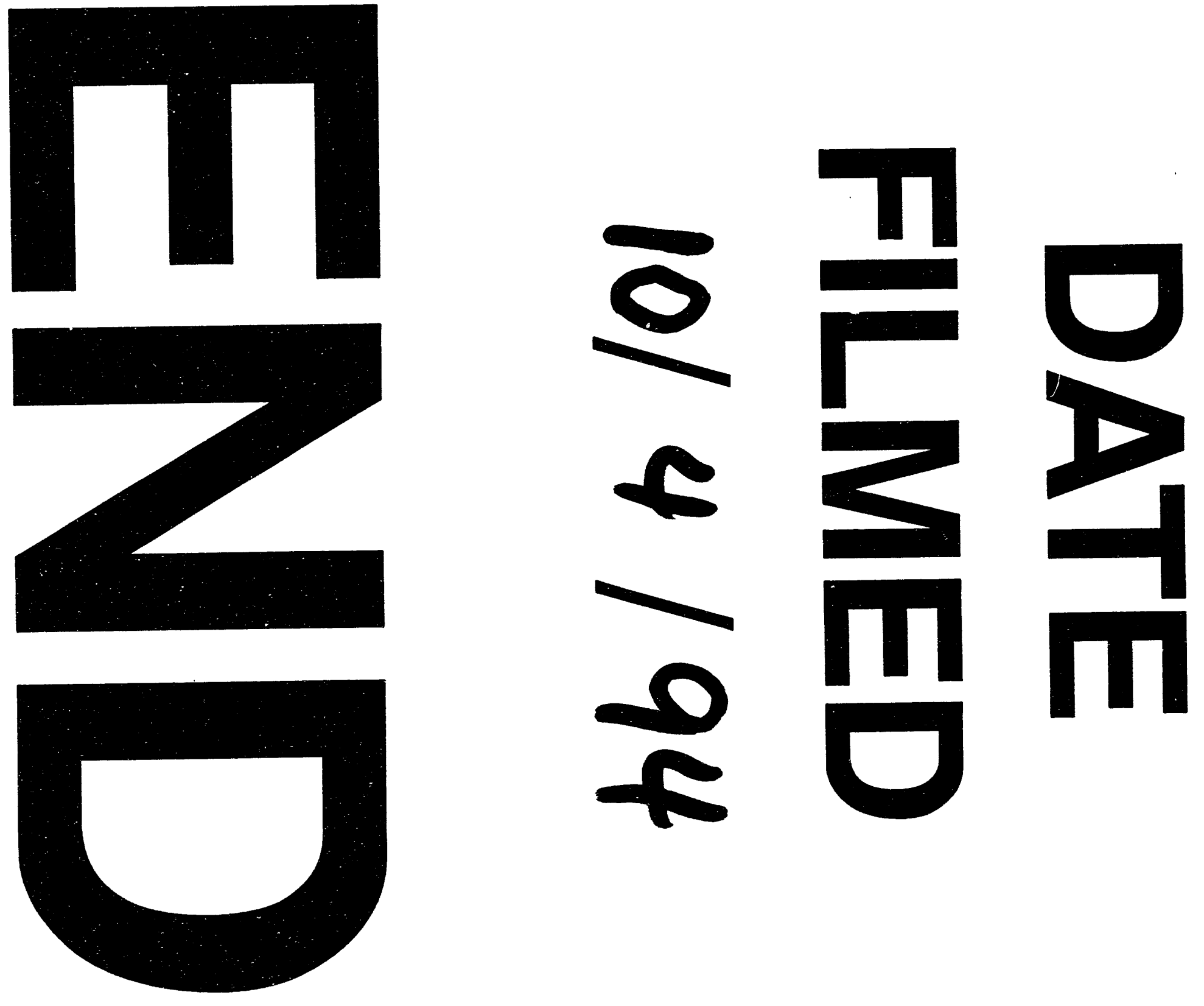
$-$ 